\title{
Synthesis of Alocasin A
}

\author{
Se Hun Kim and Jonathan Sperry* \\ School of Chemical Sciences, University of Auckland, 23 Symonds St., Auckland, New
}

Zealand

\section{SUPPORTING INFORMATION}




\section{Contents}

Page

3

${ }^{1} \mathrm{H}$ NMR spectrum of $\mathbf{3}\left(\mathrm{CDCl}_{3}\right)$

4

${ }^{13} \mathrm{C}$ NMR spectrum of $\mathbf{3}\left(\mathrm{CDCl}_{3}\right)$

5

${ }^{1} \mathrm{H}$ NMR spectrum of $\mathbf{4}$ (Acetone- $d_{6}$ )

6

${ }^{13} \mathrm{C}$ NMR spectrum of 4 (Acetone- $d_{6}$ )

7

${ }^{1} \mathrm{H}$ NMR spectrum of alocasin $\mathrm{A}(\mathbf{1})\left(\mathrm{CD}_{3} \mathrm{OD}\right)$

8

${ }^{13} \mathrm{C}$ NMR spectrum of alocasin $\mathrm{A}(\mathbf{1})\left(\mathrm{CD}_{3} \mathrm{OD}\right)$ 


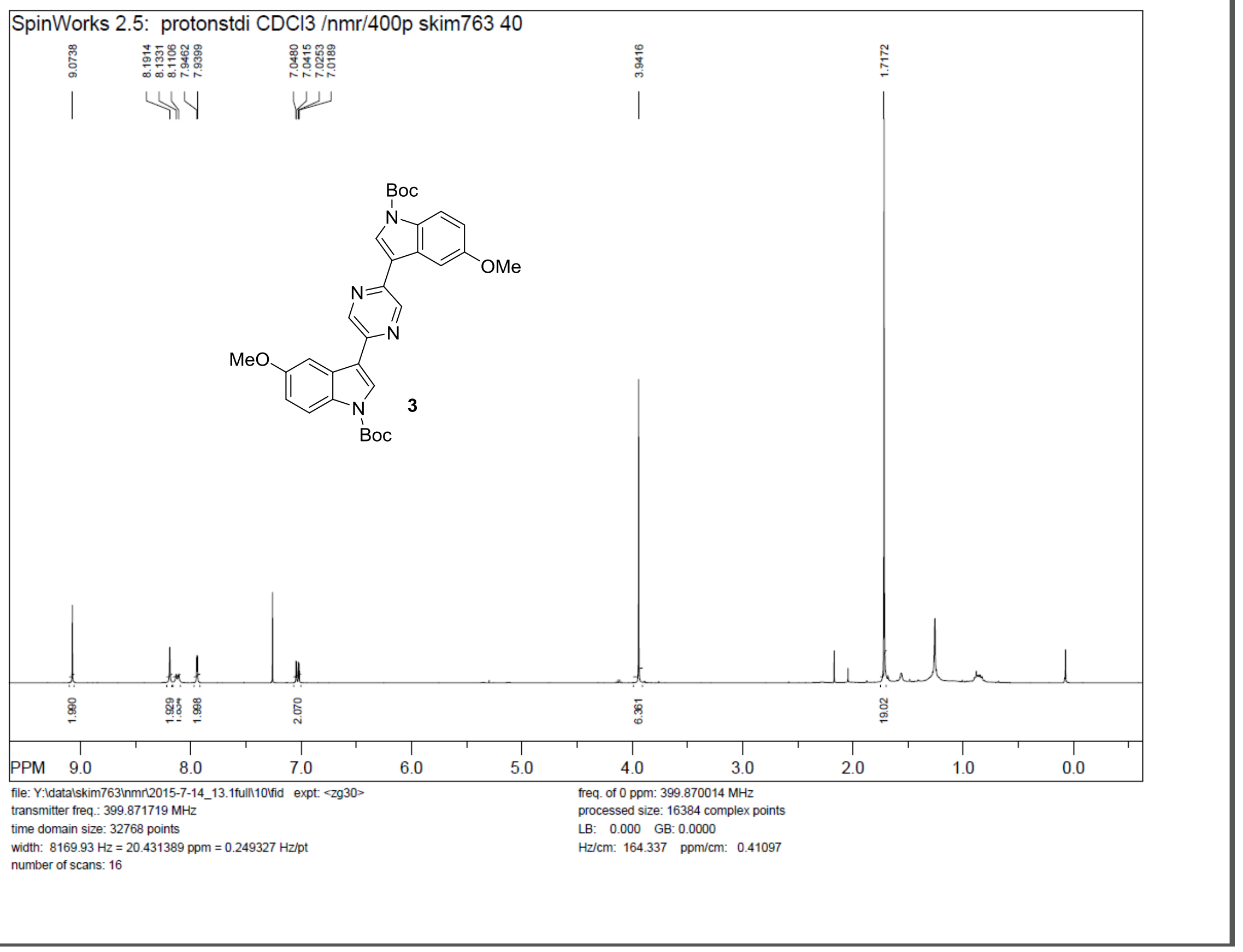




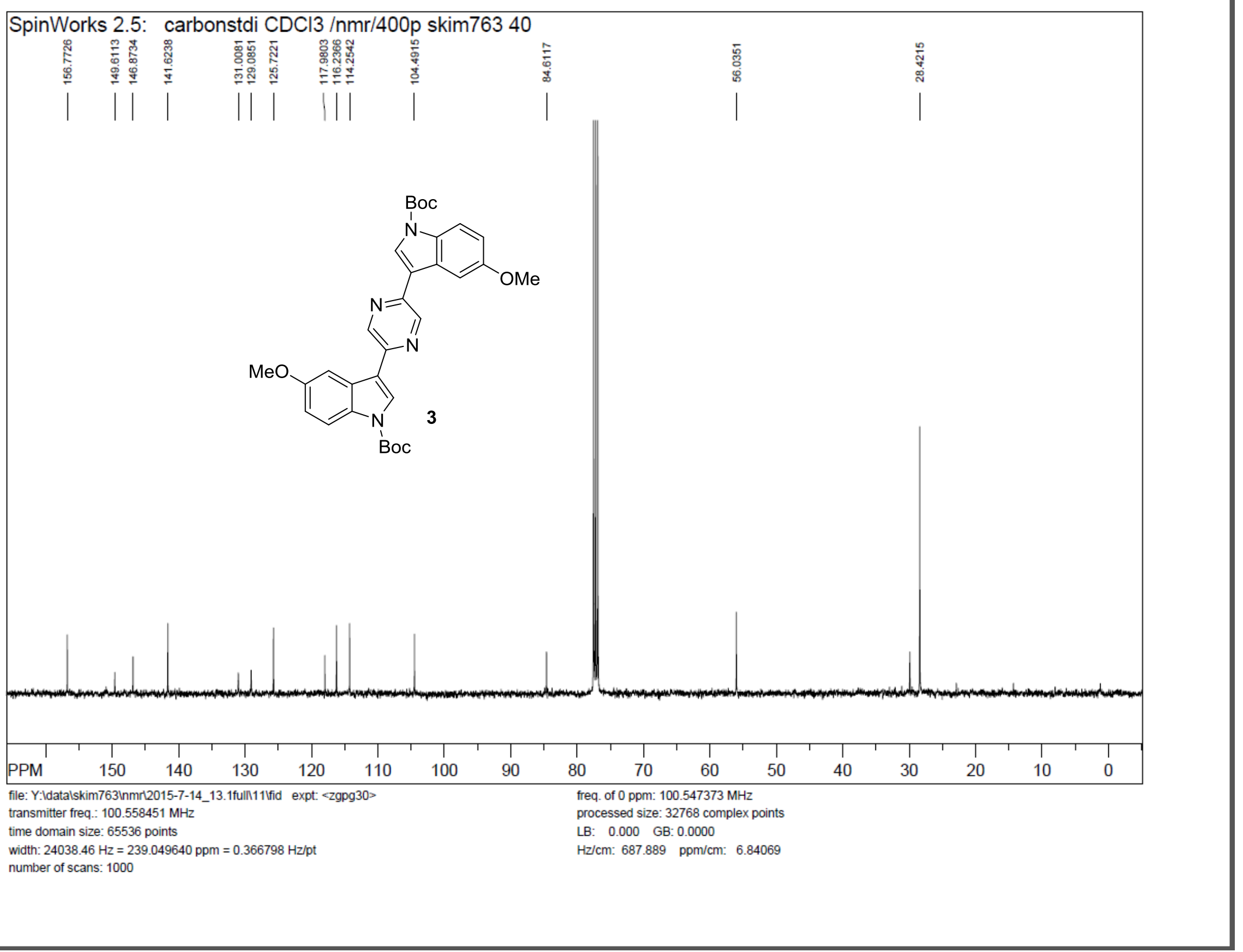




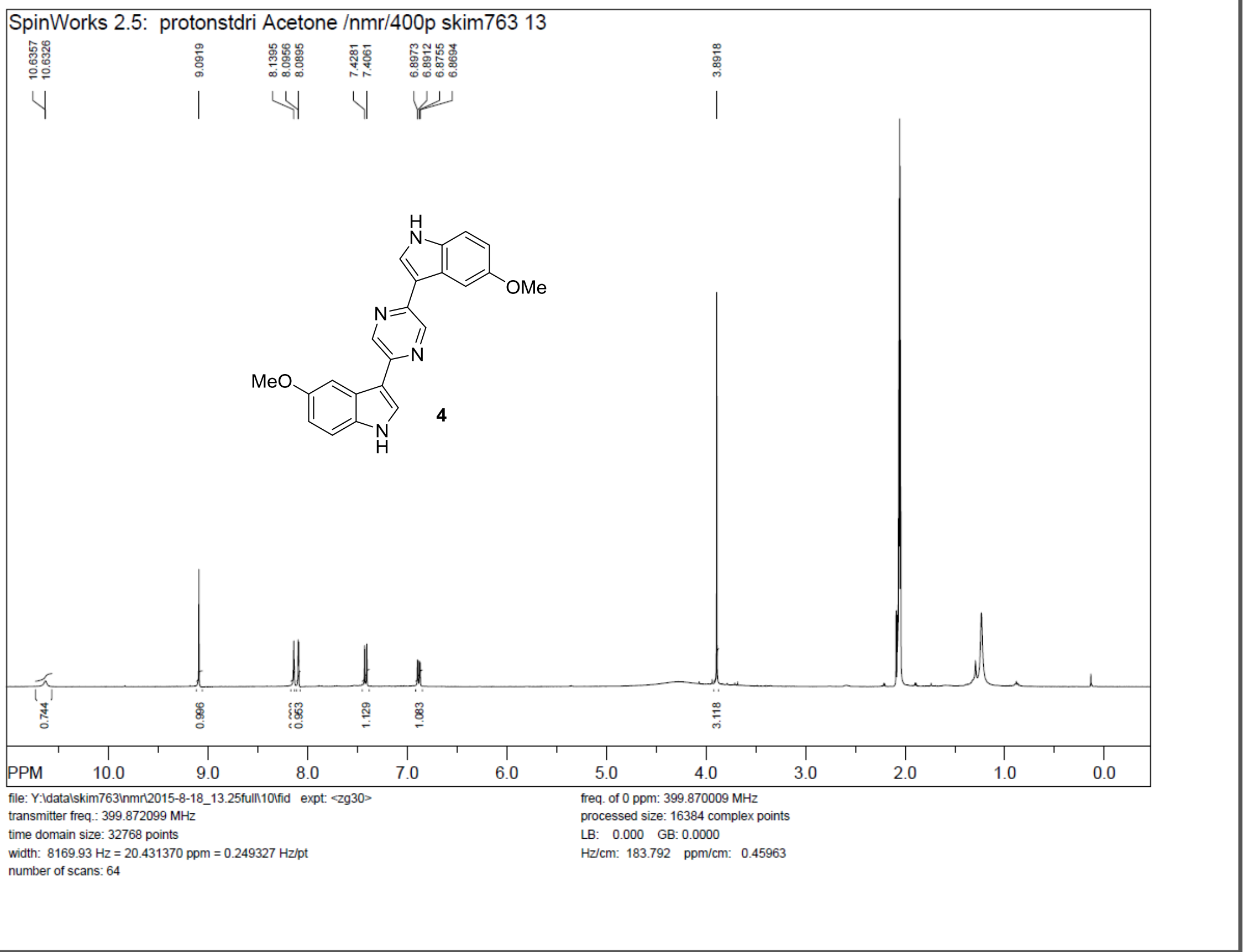




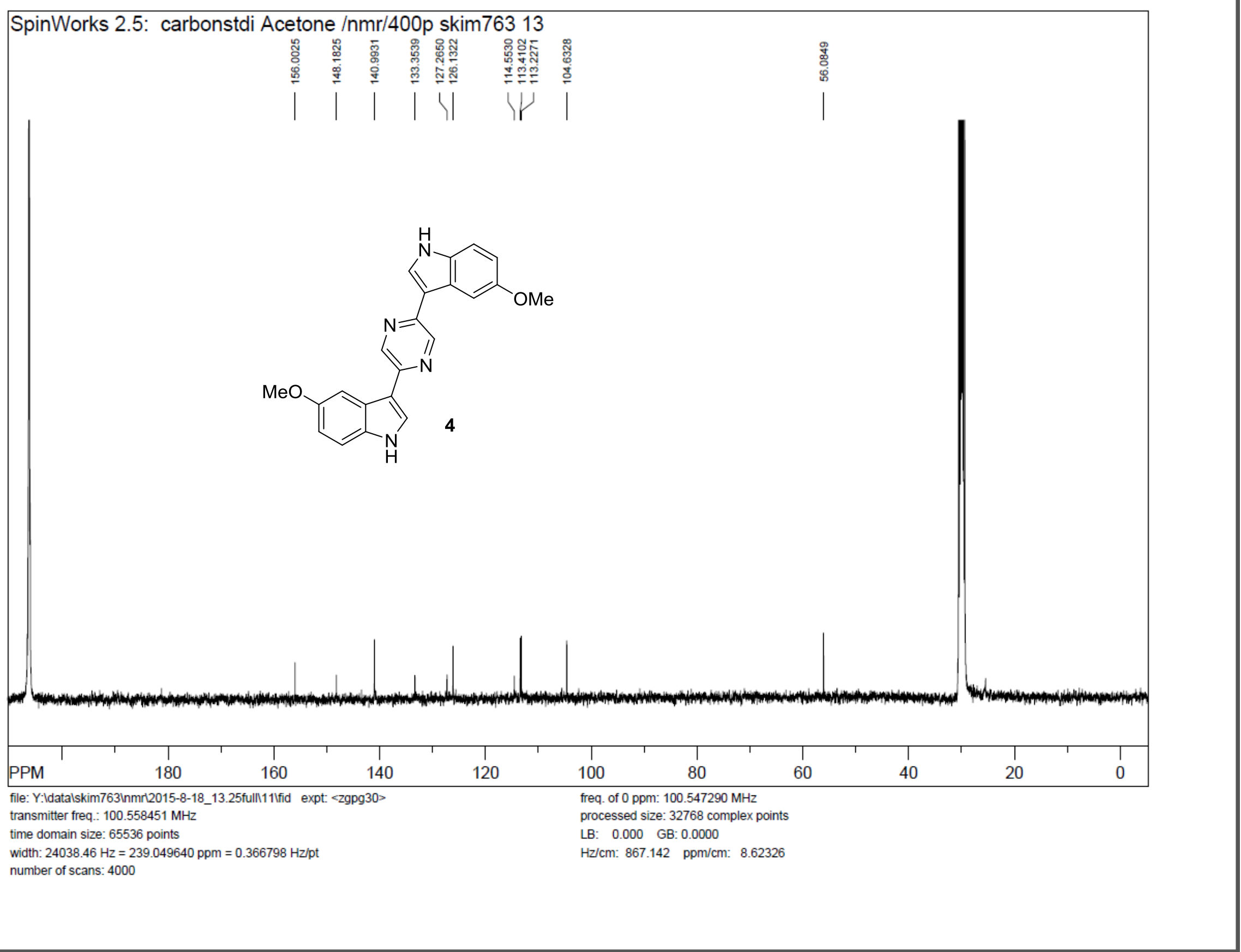




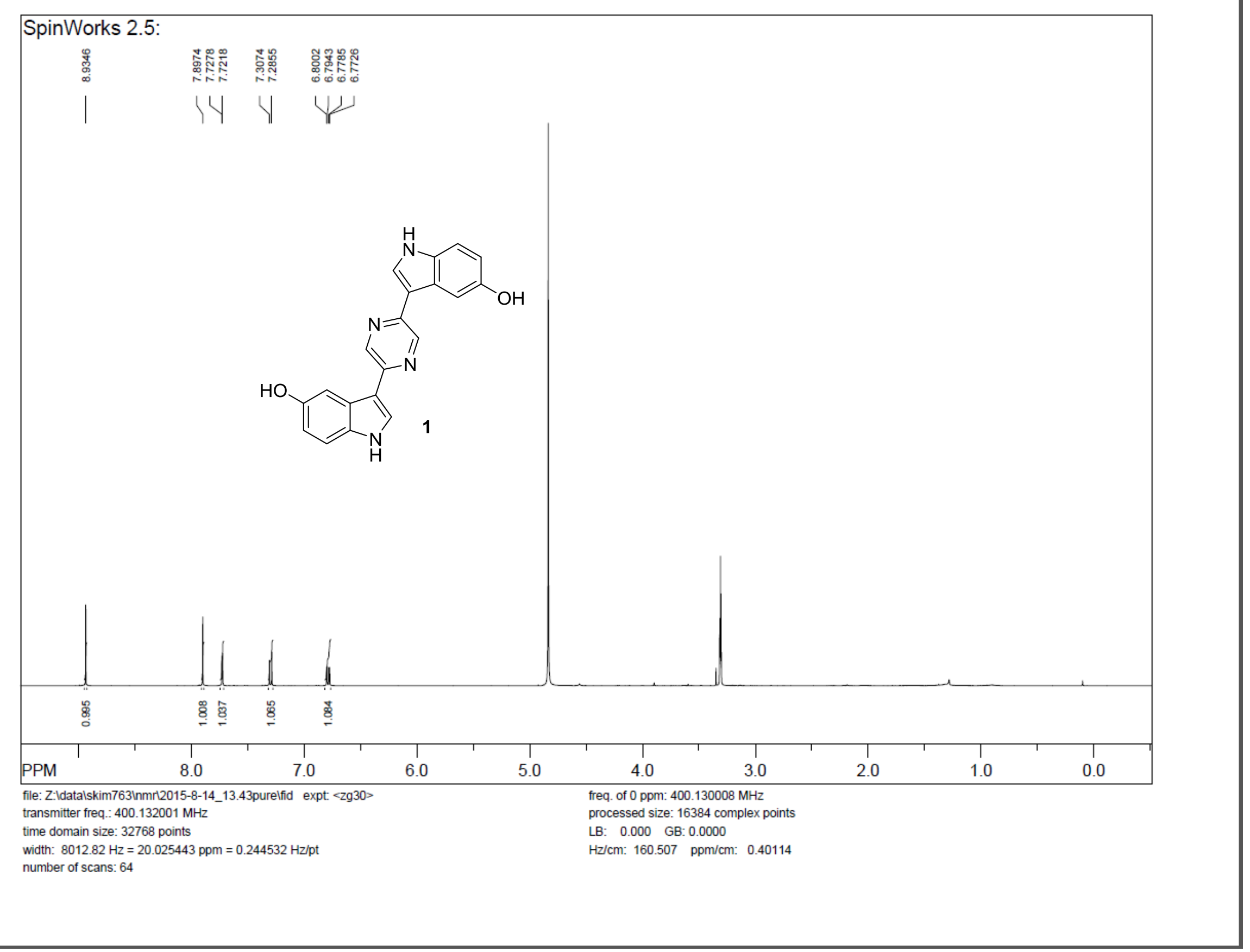




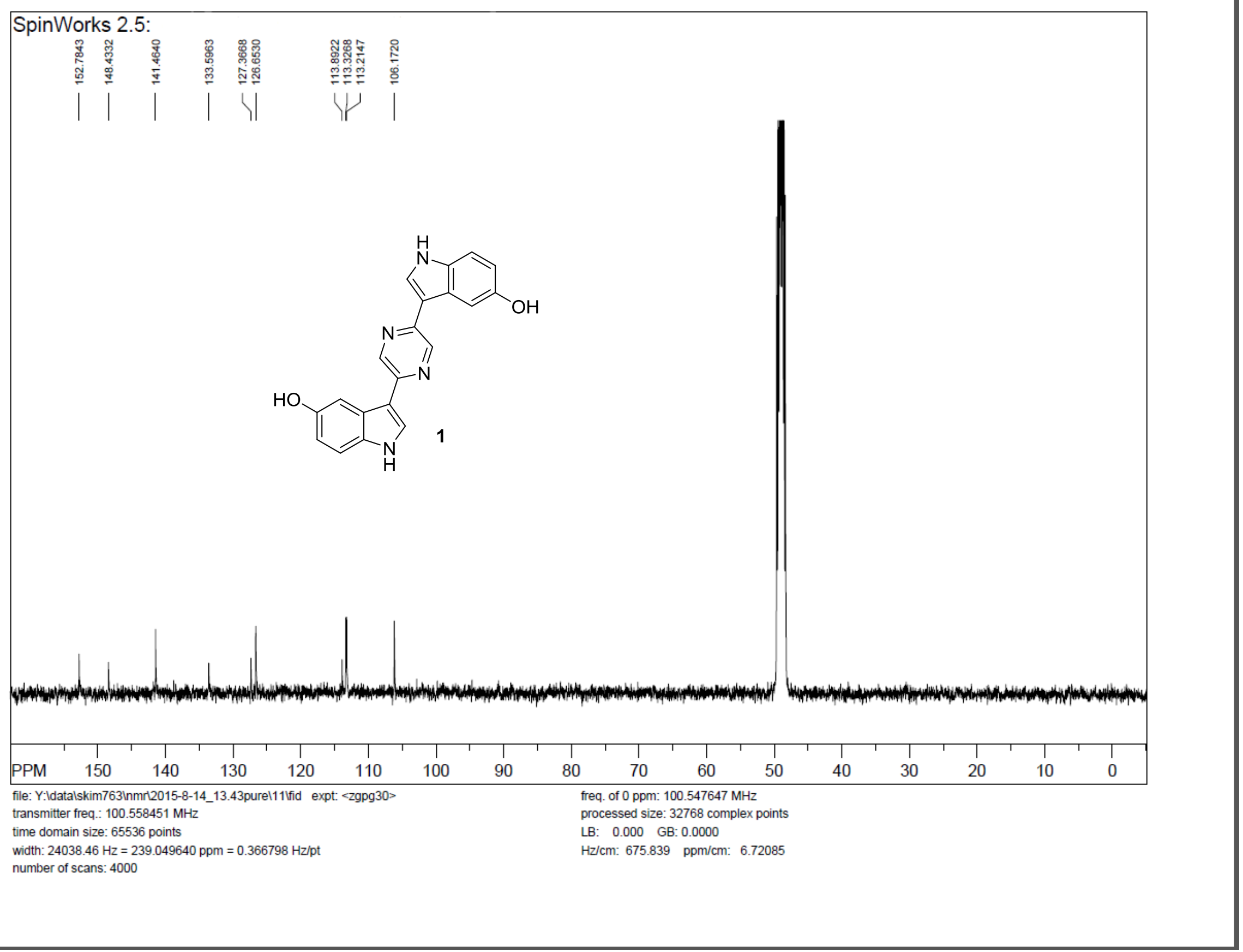

